patients accordingly will quite correctly be censured for professional negligence. Obviously it will still be up to patients to decide for themselves, but the GP will need to present all the known facts to each patient so that they are well informed.

Hopefully the human side of general practice will continue, or even grow, for most of us wish to remain the trusted family physician to whom our patients can turn in times of trouble. However, with increasing numbers of female graduates (many of whom cannot work full time because of other commitments), shorter working weeks, an unwillingness to do home visits and out-of-hours cover, and lengthening holidays and study leave, where will we be when our patients need us ? We have no divine right to our patients' loyalty and respect and perhaps not many people would mourn our passing if the new primary care helper to whom they turned had a degree in sociology and computer science.

As regards to the situation today, many computer experts would totally disagree with the statement that "present computer systems are relatively expensive and unreliable." Effective and reliable information systems are now available at costs ranging from $40 \mathrm{p}$ per patient per annum for a basic record summary up to $£ 1$ per patient per annum for a full encounter system with repeat prescription facilities. These costs are inclusive of all software and maintenance and running costs. Projected costs over the next few years will fall slightly. However, costs will never come down if there is no market for the system, so the policy of "wait and watch the prices fall" is a false one. It has been repeatedly pointed out that the average GP is now responsible for spending over $£ 150000$ a year of the resources of the NHS. It seems sensible to allocate less than $1 \%$ of this to an effective information system, which could pay for itself several times over with safer and more effective prescribing, less iatrogenic disease, and more appropriate referral. The fact that there is so little evidence of the effect of computerised information systems on general practice is a reflection of the low priority given to them by the profession and the DHSS alike. We support your call for many more pilot studies and agree that improvements in patient care must be demonstrated.

We may never have a more opportune time to invest and experiment in computerised information systems and records. If we keep our heads in the sand for much longer we may find that everyone has gone on without us. Computers, video sets, and improved communication networks will be the growth area of the next two decades. Whether we like it or not, they must also be a growth area in general practice. As the old saying goes, if you don't like the destination perhaps you'd better get off the train.

M G SHELDON

University Department of Community

Health,

University Hospital,
Nottingham NG7 2UH

Durham

A Malcolm

\section{HLA and disease 1980}

SIR,-The mechanisms suggested to explain the association of HLA with disease, reviewed in your leading article (21 June, p 1485), were classified either as two-gene theovies or as one-gene theories, whereby the HLA antigen either cross-reacts with some infectious agent or acts as a receptor for such an agent. The main evidence favouring the two-gene theory was the presence in mice of "immune response genes" within the H-2 complex, although no such human genes had so far been identified. However, mouse "IR" genes have not been identified either, and the term represents a semantic abbreviation for the evident demonstration of high and low immune responses in different species of inbred mice when injected with the same dose of antigen, and the data could equally well be explained by a molecular mimicry hypothesis. ${ }^{12}$

Ankylosing spondylitis remains the model par excellence for studying HLA and disease. Partial cross-reactivity between HLA-B27 lymphocytes and Klebsiella has been obtained using both rabbit $\operatorname{sera}^{3} 4$ and tissue typing sera,${ }^{5}$ although only the latter can be used as evidence for suggesting a direct link between HLA-B27 itself and Gram-negative bacteria, since monospecific xenogeneic typing sera have so far not been produced. ${ }^{6}$ Klebsiella micro-organisms have been isolated during the active phase of the disease, ${ }^{7}$ including uveitis, ${ }^{8}$ and similar results have been obtained by another group. ${ }^{9}$

The chief merit of the molecular mimicry hypothesis, despite the controversial issue of Klebsiella ${ }^{10}$ is that it provides a mechanism for the pathogenesis of the disease, in that anti-Gram-negative bacterial antibodies binding to HLA-B27-positive chondrocytes, through complement activation, could produce spinal disease. The theory can be tested by investigating differential distribution, according to HLA type, of natural antibodies evoked by gut flora; and such studies are currently in progress.

Immunology Unit,

Department of Biochemistry,

Queen Elizabeth College,

${ }^{1}$ Ebringer A, Davies DAL. Nature (New Biol) 1973; 241:144-7.

Wooley.

bringer A, Cowling P, Ngwa Suh, et al. In: Dausset INSERM $1976 ; 58: 27$.

Welsh J, Avakian H, Cowling P, et al. Br $\mathcal{F}$ Exp Path 1980;61:85-91.

Avakian H, Welsh J, Ebringer A, Entwistle CC. Br F Exp Path 1980;61:92-6.

6 Bodmer WF. $\mathcal{F}$ R Coll Phys Lond 1980;14:43-50

Ebringer R, Cooke D, Cawdell DR, et al. Rheum Rehab 1977;16:190-6.

1979; $; .383$, Cawdell DR, Ebringer A. Br Med f $1979 ; \mathrm{i}: 383$

Eastmond. CJ, Willshaw HE, B
Ann Rheum Dis $1980 ; 39: 118-23$. Ann Rheum Dis 1980;39:118-23.
Warren RE, Brewerton DA, Ann Rheum Dis 1980;
39:37-44.

\section{Drugs and rheumatoid arthritis}

SIR,-In their article on the effects of drugs on the manifestations of rheumatoid arthritis Professor V Wright and Dr R Amos (5 April, p 964) end by saying that radiological assessment over a long period is needed to show whether a drug favourably affects the course of rheumatoid arthritis.

They include corticosteroids among drugs and refer to the first controlled trials of their use run by a joint Medical Research Council and Nuffield Foundation committee specially formed for the purpose. They omit to mention, however, the two striking findings of those trials. ${ }^{1}$ The first was that prednisolone had a markedly favourable effect on the manifestations of early rheumatoid : arthritis, which cortisone did not. This finding has yet to be accounted for. The second was that, in the prednisolone trial only, the incidence of new bone erosions was strikingly less than in the aspirin and other analgesics control group over a period of two years. The radiological assessment was continued by the co-ordinator for a further three years and the reduction, though less, was still marked. This finding that prolonged prednisolone therapy, at a dose of $10-12 \mathrm{mg}$ each day, resulted in potentially affected bone retaining its integrity is of major interest in the study of rheumatoid arthritis but does not justify the routine use of this hormone. In consequence the latter finding was published in an article on general rheumatoid arthritis research and not on treatment. ${ }^{2}$

The picture, to my mind, is of a tissue concentration of prednisolone able to prevent the initiation of an inflammation that it could not suppress once started, and of the more easily metabolised cortisone in a theoretically equivalent dose being unable to do so. (Cortisone and cortisol are interconvertible throughout the body; the former is the inactive form.) To the author this is a complex matter as in his opinion treatment with adrenocorticotrophic hormone, producing an equivalent dose of cortisol, is also effective.

The fact that this interesting effect of prednisolone has parallels in the treatment of other diseases increases the need to know its nature.

\section{H F WEST}

Axminster, Devon EX13 5TL

${ }^{1}$ Joint Committee of the Medical Research Council and the Nuffields Foundation on clinical trials of cortisone, ACTH, and other therapeutic measures in chronic rheumatic diseases. Ann Rheum Dis

${ }^{2}$ West HF. Abst World Med 1967;41 :401-17.

\section{Must plagiarism thrive?}

SIR,-The recent outbreak of flagrant plagiarism referred to by your special correspondent ( 5 July, $p$ 41) belongs to a long tradition of scientific theft. One is reminded of the great Tom Lehrer's bitter comment on scientific endeavour, "Why the Good Lord made your eyes-... to plagiarise ...."”

Few thieves have been as blatant as $\mathrm{Dr}$ E A K Alsabti, but in the 1930s a French mathematician, Maurice de Duffahel, published a number of papers which were wordfor-word copies of classical papers of previous decades $^{1}$; and as recently as the late 1960 s a paper was published in the Proceedings of the fapanese Physical Society which was a complete copy of a paper by a British physicist. ${ }^{2}$.

Much more common is the theft of ideas without acknowledgment and the failure to quote foundational work of other authors, so that derivative studies are passed off as original. Hagstrom found that $52 \%$ of 1309 scientists thought that they had been abused in this way ${ }^{3}$ and Gaston, who interviewed 203 high-energy physicists, discovered that half of them felt that the other researchers failed to cite their articles when a reference was clearly called for. ${ }^{2}$ Whether this is scientific paranoia is hard to say. I have myself twice had the experience of seeing other workers with access to resources that I cannot command publish without acknowledgment results based on ideas that I have discussed with them over coffee at scientific meetings.

If anyone should think that they have seen some of this letter before, I must admit that I have lifted some of the information from an article by Eugene . Garfield, published seren- 